\title{
Interlayer Influence on Timber-LWAC Composite Structures with Screw Connections
}

\author{
Luis Filipe Carvalho Jorge, Ph.D. ${ }^{1}$; Sergio Manuel Rodrigues Lopes, Ph.D. ${ }^{2}$; and \\ Helena Maria Pires Cruz, Ph.D. ${ }^{3}$
}

\begin{abstract}
Timber-concrete composite structures are often used as upgrade solutions for existent timber floors. The timber cross section is maintained and a concrete layer is poured over the floorboard surface. Floorboards help with loading distribution on the beams. The study presented is based on laboratory tests that used specimens made with a lightweight aggregate concrete (LWAC). The use of this type of concrete, compared with normal weight concrete (NWC), has the advantage of lower dead weights, and might be very important in many cases, namely, when the supporting structure has limited strength. Many design works of timber-concrete composite connections do not take into account the timber interlayer, which is known to reduce the load-carrying capacity and the stiffness of the connection. Previous investigations of NWC found that the inclusion of the interlayer leads to average reductions of $30 \%$ and $50 \%$ for the load capacity and slip modulus, respectively. The current investigation with LWAC found that such reductions are up to 10 and $30 \%$, respectively. DOI: 10.1061/(ASCE)ST.1943-541X.0000299. (C) 2011 American Society of Civil Engineers.
\end{abstract}

CE Database subject headings: Composite structures; Wood; Lightweight concrete; Laboratory tests; Bending; Interfaces; Rehabilitation; Connections.

Author keywords: Wood structures; Composite beams; Lightweight concrete; Laboratory tests; Bending; Interface shear; Rehabilitation.

\section{Introduction}

The timber-concrete composite construction system is a possible solution for building new slabs but the solution is especially competitive in cases where a timber floor already exists and the owner wants to rehabilitate it. The pouring of concrete on the floorboard is a simple operation, provided that some precautions (such as placing a film to prevent wetting the timber and leakage) are taken.

This solution has also some structural advantages. For instance, the load-carrying capacity of the floor is significantly increased, which is often required after the new functionality. This redesign procedure normally implies an increase of the live loads, at least to meet the new demands of the current codes that are different from those that existed when the wooden slab was originally constructed. The new requirements of deflections and vibrations could also be a problem for a timber-only solution, and these parameters are much more efficiently controlled by using a timber-concrete composite solution, because of a higher value of the bending stiffness modulus when the concrete is added to the cross section. Adding the concrete layer to the timber floor also increases significantly the

${ }^{1}$ Lecturer, Polytechnic Institute of Castelo Branco, Av. Pedro Álvares Cabral, 12, Castelo Branco, 6000-084, Portugal. E-mail: luisfc@est.ipcb.pt

${ }^{2}$ Professor, Dept. of Civil Engineering, FCTUC, Polo II, Univ. of Coimbra, Coimbra, 3030-290, Portugal (corresponding author). E-mail: sergio@dec.uc.pt

${ }^{3}$ Researcher, LNEC - National Laboratory of Civil Engineering, Av. do Brasil, 101, Lisboa, 1700-066 Lisboa, Portugal. E-mail: helenacruz@lnec .pt

Note. This manuscript was submitted on August 24, 2009; approved on August 20, 2010; published online on August 25, 2010. Discussion period open until October 1, 2011; separate discussions must be submitted for individual papers. This paper is part of the Journal of Structural Engineering, Vol. 137, No. 5, May 1, 2011. CASCE, ISSN 0733-9445/2011/5-618$624 / \$ 25.00$. floor capacity to distribute loads on the transversal direction, which was one of the weak points of the single timber floor with a $T$-type cross section (Fig. 1). Furthermore, nonstructural functions could also be improved with concrete. This is the case of thermal and sound isolation.

One of this construction technique's biggest advantages is that there is less disturbance at the level below the floor that is being rehabilitated. Maintaining the floorboards also avoids the use of formwork when pouring the concrete. Nevertheless, a plastic foil must be placed over the floorboards, because of natural breaks within the floorboards. This prevents any possible leakage.

From the structural point of view, this interlayer has no value for the bending stiffness, and thus, the analysis of the cross section should only consider the two layers, and neglect the middle layer (floorboards). However, in comparison with the cross section without interlayer, there is a slight increase in the height of the cross section that compensates for the lack of stiffness of the interlayer. In the most common connection types, the interlayer introduces a gap that tends to reduce the slip modulus and the load capacity of the connection.

With mechanical fasteners, the construction feasibility should not be much affected, but with other connection types, such as those using direct contact between timber and concrete to transfer shear, the implementation of this construction technique could be much more complex and might require extra work for its construction.

Some results of the connection behavior were presented in other articles (Dias et al. 2007; Steinberg et al. 2003; Fragiacomo 2006; Fragiacomo and Ceccotti 2006) also presented a numerical study of the issue. The current article presents results for experimental shear tests and full size beams. The specimens were made with lightweight aggregate concrete. 